\title{
WestVirginiaUniversity
}

THE RESEARCH REPOSITORY @ WVU

Graduate Theses, Dissertations, and Problem Reports

2017

\section{Central supply company noise survey.}

Janice Drelick

Follow this and additional works at: https://researchrepository.wvu.edu/etd

\section{Recommended Citation}

Drelick, Janice, "Central supply company noise survey." (2017). Graduate Theses, Dissertations, and Problem Reports. 3983.

https://researchrepository.wvu.edu/etd/3983

This Problem/Project Report is protected by copyright and/or related rights. It has been brought to you by the The Research Repository @WVU with permission from the rights-holder(s). You are free to use this Problem/Project Report in any way that is permitted by the copyright and related rights legislation that applies to your use. For other uses you must obtain permission from the rights-holder(s) directly, unless additional rights are indicated by a Creative Commons license in the record and/ or on the work itself. This Problem/Project Report has been accepted for inclusion in WVU Graduate Theses, Dissertations, and Problem Reports collection by an authorized administrator of The Research Repository @ WVU. For more information, please contact researchrepository@mail.wvu.edu. 


\title{
Central Supply Company Noise Survey
}

\author{
by
}

Janice Drelick

Problem Report submitted to the Statler College of Engineering and Mineral Resources

at West Virginia University in partial fulfillment of the requirements

for the degree of

Master of Science

in

Industrial Hygiene

Dr. Steve Guffey, Chair

Dr. Kevin He

Mr. Marc Wamsley

Industrial Management and Systems Engineering Department

Morgantown, West Virginia

2017 


\section{Abstract \\ Central Supply Company Noise Survey}

\section{Janice Drelick}

Central Supply Company was interested in having a noise survey completed at two locations, a concrete batch plant and a block manufacturing plant. Noise levels were measured to evaluate the current hearing conservation program and to determine potential overexposure, compliance, and appropriateness of protection.

Employee dosimetry results showed that sound levels at the concrete batch plant were not high enough to require employee enrollment in a hearing conservation program. At the block manufacturing plant, employee dosimetry results showed there was a need for a hearing conservation program, including a need for hearing protection to be worn at all times during production. 


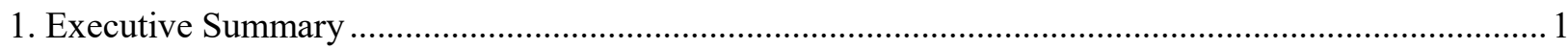

2. Purpose

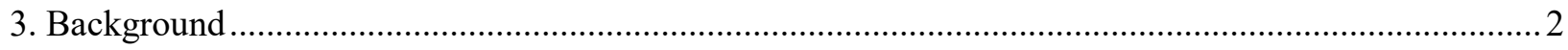

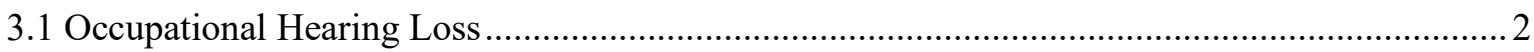

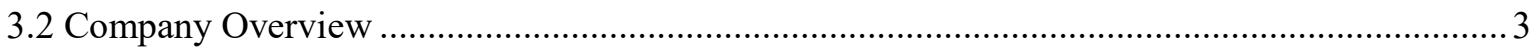

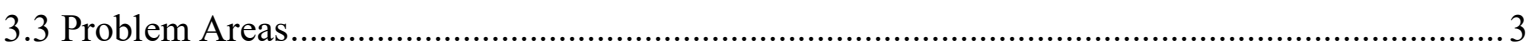

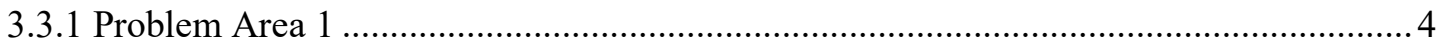

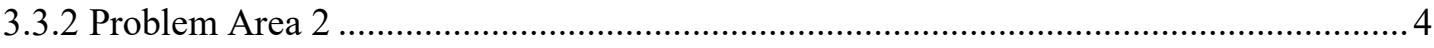

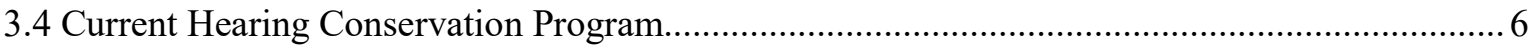

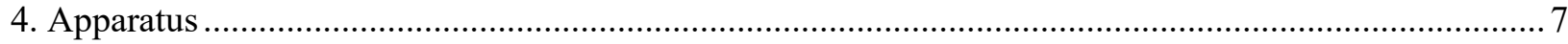

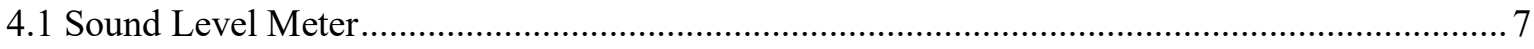

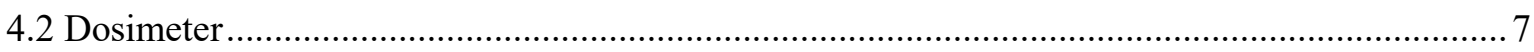

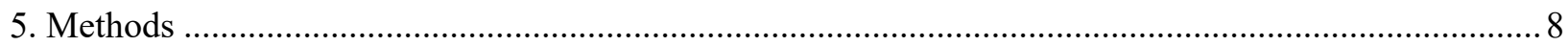

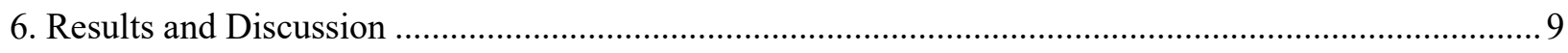

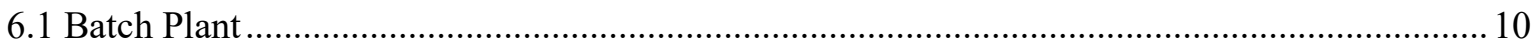

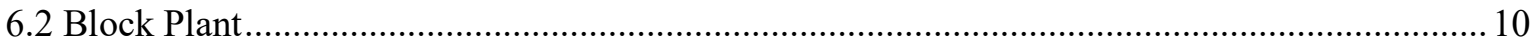

6.2.1 Adequacy of Hearing Protection .............................................................................. 10

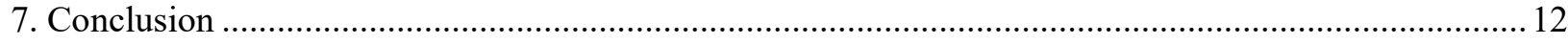

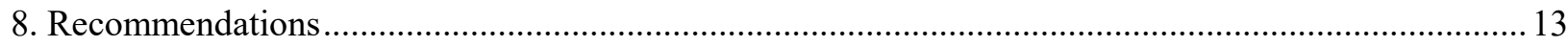

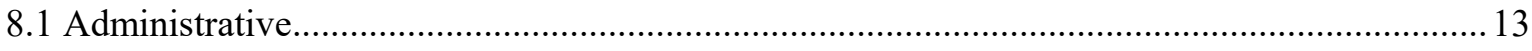

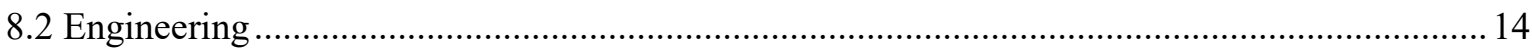

8.3 Personal Protective Equipment .................................................................................. 14

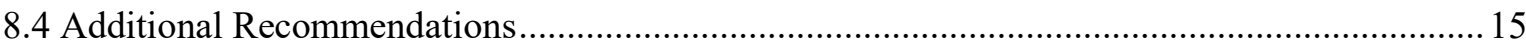

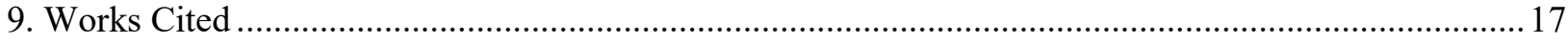

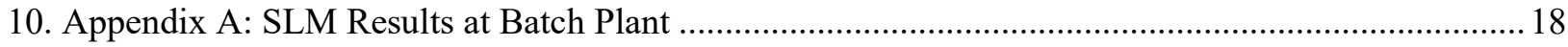

11. Appendix B: Adjustments for Shifts > 8 Hours ….......................................................................... 19

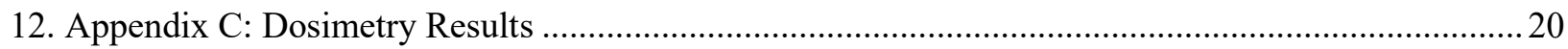

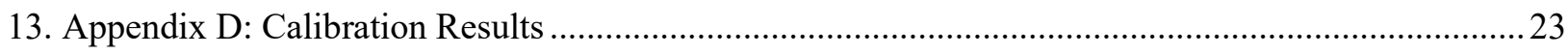

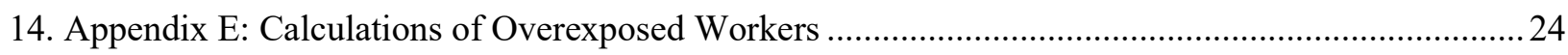

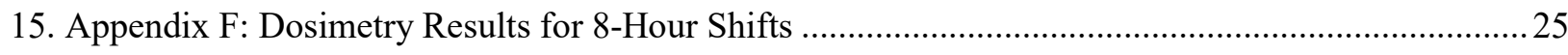




\section{Executive Summary}

The objective of this report was to evaluate noise levels to determine potential overexposure at two separate facilities of Central Supply Company. Noise levels were determined through monitoring in the form of dosimetry and area sampling. These noise levels were then compared to the Permissible Exposure Limit set forth by the Occupational Safety and Health Administration's (OSHA) occupational noise exposure standard 29 CFR 1910.95.

Individual dosimetry results showed that sound levels at the concrete batch plant were not high enough to require employee enrollment in a hearing conservation program. It was found that neither of the two drivers tested at the Batch Plant exceeded the OSHA action level of $85 \mathrm{dBA}$ for an 8-hour work day, thus not exceeding the permissible exposure limit of $90 \mathrm{dBA}$ either.

Employee dosimetry results at the block manufacturing plant showed there was a need for enrollment in the hearing conservation program, as well as the need for hearing protection to be worn at all times during production. Without hearing protection, all employees tested exceeded both the OSHA action level and the PEL. With the current hearing protection, only one out of the three employees at the Block Plant exceeded the OSHA action level, but did not exceed the PEL. It is important to note that this survey is limited to the noise produced on October 24, 2016 and on November 16, 2016. Any increase or change in production or change in the manufacturing process could affect the workers' exposures.

\section{Purpose}

The Safety and Environmental Manager of Central Supply Company ("Central” or “Company”), Marc Wamsley, was contacted by Janice Drelick with the request to perform a noise survey through the West Virginia University Industrial Hygiene Program. The Company 
was interested in having two facilities monitored in Buckhannon, WV. Testing was primarily focused on determining whether noise levels exceeded $85 \mathrm{dBA}$ or $90 \mathrm{dBA}$ in an 8-hour timeweighted average (TWA) as per OSHA's Noise Exposure Standard 29 CFR 1910.95. In addition, the hearing conservation program $(\mathrm{HCP})$ of the Company was evaluated to determine compliance and the appropriateness of current hearing protection. Recommendations for any needed corrective actions are given in this report.

\section{Background}

Noise induced hearing loss is one of the most common occupational illnesses. It is often overlooked because they are no visible effects and, except for some rare cases, there is no pain. Noise is considered hazardous when it reaches 85 decibels or higher. At this level, it is difficult to speak to someone at an arm's length away.

\subsection{Occupational Hearing Loss}

Occupational hearing loss is caused by prolonged exposure to noise in a work environment and is a prevalent occupational health concern in the United States today (Ali, 2012). The National Institute for Occupational Safety and Health (NIOSH) has estimated that approximately 22 million workers are exposed to hazardous noise levels in the workplace (Martinez, 2012).

Occupational hearing loss occurs gradually and most workers are unaware they are being affected. Noise levels high enough to cause irreversible hearing loss require proper preventative measures, such as OSHA required Hearing Conservation program.

To satisfy OSHA requirements hearing conservation programs must include monitoring, audiometric testing, adequate hearing protection, training, and recordkeeping. They are designed 
to protect employees from hearing loss due to hazardous levels of noise (OSHA, 1995). The Occupational Safety and Health Administration requires that employers provide hearing conservation programs for their employees where noise levels are equal to or exceed an 8-hour time-weighted average of $85 \mathrm{dBA}$ (OSHA, 2017). This $85 \mathrm{dBA}$ threshold is referred to as the "Action Level", above which unprotected exposures are unacceptable.

Noise surveys are conducted using dosimeters and sound level meters which measure noise levels in decibels $(\mathrm{dB})$. When used as criteria for HCPs (hearing conservation programs), these instruments must be set to measure on the A scale, which narrows the instruments sensitivity to largely exclude very high and very low frequencies to mimic the frequency range perceived by the human ear. OSHA has determined that at $90 \mathrm{dBA}$ averaged over an 8-hr period, the permissible exposure limit (PEL) has been reached and $100 \%$ of the allowable dose has been received. OSHA has set an exchange rate of $5 \mathrm{dBA}$, meaning for every $5 \mathrm{dBA}$ increase in the time-weighted average, the allowed dose is halved.

\subsection{Company Overview}

Central Supply Company is a block manufacturer and ready mix producer with multiple locations throughout West Virginia. The company consists of nine ready mix concrete plants, one block plant and five building supply stores. There are currently 217 people employed at Central servicing Northern and Central West Virginia, Southwest Pennsylvania, and Western Maryland.

\subsection{Problem Areas}

There are two areas that the Company was interested in having monitored. The noise levels at these facilities made it difficult to have normal conversation, which suggest that the decibel levels may be above the permissible exposure limit. 


\subsubsection{Problem Area 1}

The first problem area is the concrete loading facility ("Batch Plant") where most of the noise exposure is located outdoors. At this facility, there are multiple concrete truck drivers and one plant manager. Previous testing indicated that noise levels in the loading area have the potential to exceed the exposure limit. The drivers at the Batch Plant drive and operate the concrete mixer trucks. These trucks use a revolving drum to mix cement with water to form concrete. The job of the driver includes filling the drum with the concrete components, operating the mixing drum, cleaning the truck, and delivering the concrete to customers. The plant manager is responsible for all duties associated with loading trucks and dispensing concrete from the silos which is done from the inside of the control room.

The main source of noise comes from truck engines during the filling process. The concern at the Batch Plant is for the truck drivers who must stand near the truck for approximately three minutes while it is being filled with concrete, which is done 3-4 times in a shift. The truck driver must use a water hose to fill the truck with water while the cement is being adding. This is done while the mixing drum is rotating at high revolutions per minute, creating the most noise. After the water hose is connected and turned on, the driver waits in the control room (which is quiet) until filling is complete.

\subsubsection{Problem Area 2}

The second problem area was the block manufacturing plant ("Block Plant") where the noise exposure is produced indoors. This facility consists of 11 employees, including forklift operators, dispatchers, and plant operators. The block press machinery is the main source of high noise levels and is located inside the building. The forklift operators remain outside during most of their shift and are not required to wear hearing protection until they enter the building. The dispatchers work in an enclosed area where noise is minimized due to sound baffling blocks. The plant manager and 
belt line workers are exposed to the most noise due to their work areas being nearest the hoppers, cement mixer, block press, and block splitter. See Figure 1 for the layout of the Block Plant.

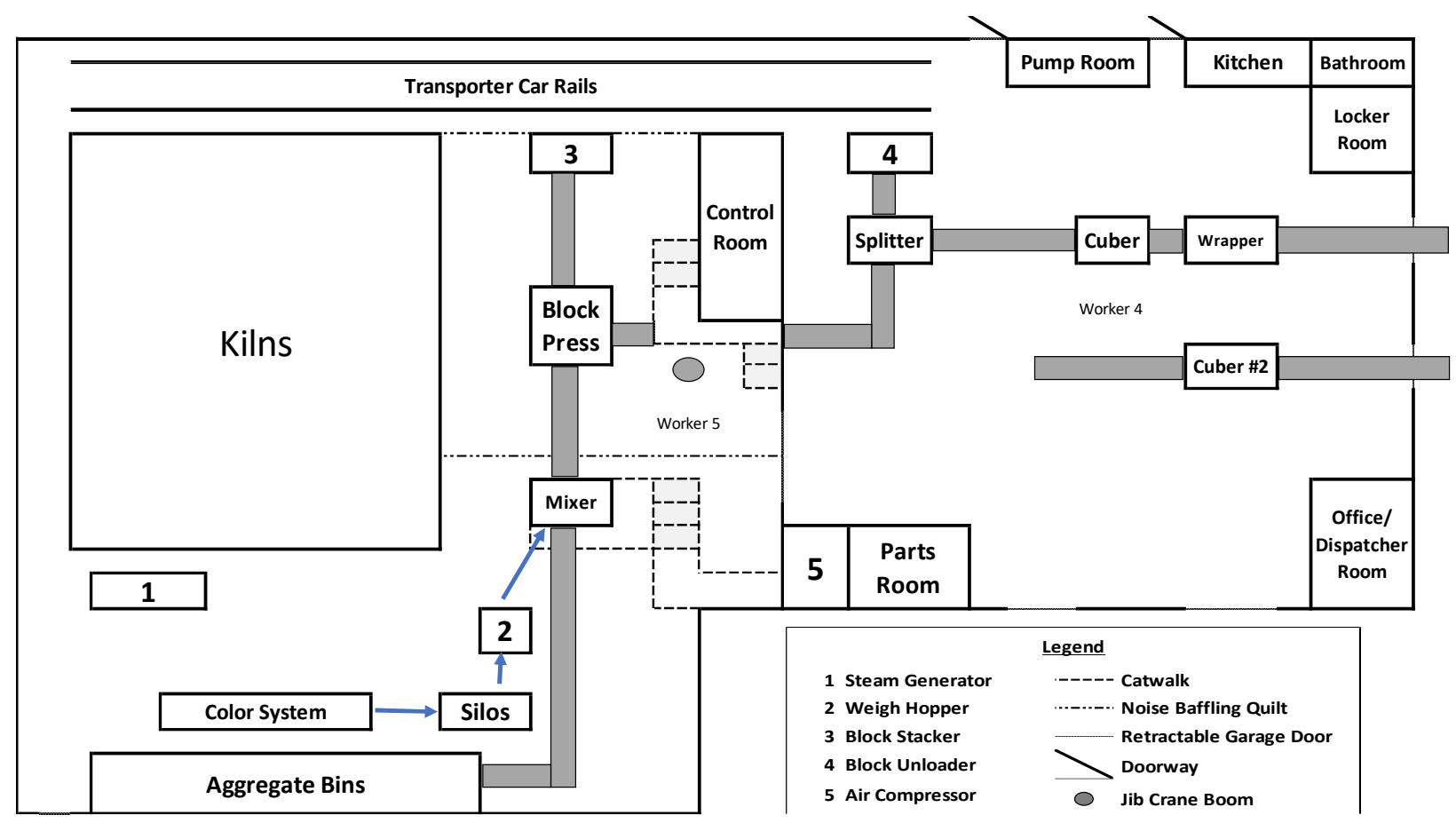

Figure 1. Layout of the Block Manufacturing Plant

The job of the plant operators includes operating forklifts, maintenance of machinery, repairing malfunctions, inspecting and stacking blocks, assembling and changing block molds, and cleaning machinery and the plant. The plant operators are also exposed to potential noise hazards during cleanup from an air chisel used to clean the inside of the cement mixer. During both days of testing, Worker 3 was responsible for monitoring and controlling the block press to insure the blocks were being molded to acceptable standards. Worker 4 was mainly on the belt line inspecting the quality of the blocks, stacking blocks, and monitoring the turntables and the cuber. There were times when he operated the forklift to move completed stacks of blocks outside of the building. The job of Worker 5 was to assemble and disassemble the block molds, which was done next to 
the block press. He also cleaned the cement mixer with an air chisel for the last two hours of the work day.

\subsection{Current Hearing Conservation Program}

Central Supply Company currently has a Hearing Conservation Program (HCP) in place. This current program includes all the required components of OSHAs hearing conservation program, which are monitoring, audiometric testing, training, protection, and record keeping. Previous monitoring was done at a different Central Supply Company facility to identify which job roles are exposed to noise levels at or above $85 \mathrm{dBA}$ in an 8-hour TWA. Central chose to include all employees who perform the same role as those found to be overexposed in the HCP. These employees consist of the mixer drivers, maintenance personnel, shop mechanics, and block plant employees. According to Marc Wamsley, Central provides annual audiometric testing for these employees. The company also provides employees with hearing plugs and muffs.

The training includes Toolbox Talks which cover a range of topics from safety, environmental, operations, and human resources with a weekly video prepared by Marc Wamsley that discusses Personal Protective Equipment (PPE) and hearing protection use. Employees in the HCP are directed on how to properly insert hearing plugs and when they should be using them. Currently, only the Block Plant employees are required to wear either hearing plugs or muffs during their shift. The provided hearing plugs have a Noise Reduction Rating (NRR) of 33. The provided hearing muffs have an NRR of 30. It was observed that employees chose to wear hearing plugs during both days of testing and no employees chose to wear the muffs. The plugs are stored in a dispenser fastened to the wall next to the break room. The muffs were observed to being laying on the work station of Worker 5 before and after use. 


\section{Apparatus}

The West Virginia University Industrial Hygiene program provided a sound level meter, five dosimeters, and a calibrator for this noise survey. This equipment was sent to the manufacturer, Larson Davis, in Provo, Utah, to be calibrated. The sound level meter (SLM) was used to make spot decibel readings and the dosimeters were used to determine time-weighted average exposures. The calibrator was used to perform the calibrations on the SLM and dosimeters before and after each shift on the two days of testing.

\subsection{Sound Level Meter}

A sound level meter measures sound by responding to changes in air pressure caused by sound waves. The Larson Davis sound level meter that was used for this noise survey is a SoundTrack LxT Class 1 with preamplifier and free field microphone. The sound levels were measured on the A scale at slow-response according to OSHA's noise standard 29 CFR 1910.95. Measurements were taken at the operator distance from the source. A Larson Davis Cal200 calibrator to perform the calibration before and after each shift. See Appendix D for procedure and results.

\subsection{Dosimeter}

A dosimeter measures sound pressure levels and integrates these measurements over a period of time. Dosimeters are typically used where noise levels tend to fluctuate or when the employees are mobile. The dosimeters used for this survey were the Larson Davis Spark 705+. The dosimeters were calibrated (see Appendix D) using the same calibrator used for the sound level. follows:

The dosimeter settings were set to correspond with OSHA requirements and are as 
- Response: Slow

- Frequency weighting: A

- Exchange Rate: 5 dBA

- Threshold: $80 \mathrm{dBA}$

- Criterion level: $90 \mathrm{dBA}$

\section{Methods}

At the Batch Plant, the sound level meter was used for area noise monitoring around four trucks during the filling process on Day 1 of testing. Readings were taken where each worker was standing. From these readings, it was determined that Truck 4 produced the highest noise levels. See Appendix A.

On Day 2 of testing, the driver of Truck 4 was selected for personal sampling using a dosimeter. The driver of a different truck of the same model was also sampled. Drivers were monitored for their 10-hour shift and noise levels were compared to OSHA's 8-hour TWA. Calculation adjustments were made to account for the difference from the 8-hour standard. See Appendix B. The job description and location of both Batch Plant employees are shown in Table 1.

A combination of both area noise monitoring and personal noise monitoring were used at the Block Plant. Personal samples were taken using the Larson Davis dosimeters. Workers were monitored for their 10-hour shift and results were compared to OSHA's 8-hour TWA, using the same adjustments as stated previously. Two days of testing was done for three employees at the Block Plant. The job description and location for each monitored employee are described in Table 1. 


\section{Table 1: Central Supply Monitored Employees}

\begin{tabular}{|c|c|c|c|c|}
\hline Worker & $\underline{\text { Job }}$ & $\underline{\text { Location }}$ & $\begin{array}{c}\frac{\text { Type of }}{\text { Required }} \\
\underline{\text { Hearing }} \\
\text { Protection }\end{array}$ & $\begin{array}{l}\frac{\text { Observed }}{\text { Wearing }} \\
\underline{\text { Hearing }} \\
\text { Protection }\end{array}$ \\
\hline 1 & Batch Plant CDL driver & Mixer Truck & $\mathrm{N} / \mathrm{A}$ & $\mathrm{N} / \mathrm{A}$ \\
\hline 2 & Batch Plant CDL driver & Mixer Truck & $\mathrm{N} / \mathrm{A}$ & $\mathrm{N} / \mathrm{A}$ \\
\hline 3 & Block Plant Operator & Block Plant (General) & plugs & sometimes \\
\hline 4 & Block Plant Operator & Belt Line/Cuber & plugs & mostly \\
\hline 5 & Block Plant Operator & Block Mold/Inside Mixer & plugs & always \\
\hline
\end{tabular}

A sound level meter was used to take noise level measurements for areas around block press, block splitter, and cement mixer. After the calibration was complete, the dosimeters were placed on each worker with the microphone positioned on the shirt collar next to their shoulders. At the end of the shift, the dosimeters were removed from each employee and the calibration was done again. See Appendix D for calibration procedure and results.

\section{Results and Discussion}

Individual dosimetry results showed that sound levels at the concrete Batch Plant were not high enough to require employee enrollment in a hearing conservation program. However, dosimetry results at the Block Plant showed that sound levels exceeded both the action level and PEL. It is important to note that production at the Block Plant was half of the typical amount on both days of testing. Testing during full production may result in higher values than given in this report. 


\subsection{Batch Plant}

According to employees, the workload during testing at the Batch Plant was normal. It was found that neither driver in the Batch Plant exceeded the OSHA action level of $85 \mathrm{dBA}$, thus, also not exceeding the OSHA PEL of $90 \mathrm{dBA}$. The highest recorded L-max between the two drivers was $113.6 \mathrm{dBA}$. The exact cause of this peak noise level is unknown due to the drivers being off site during most of the day. Further, the SLM never returned a value greater than $101.5 \mathrm{dBA}$. There was no point at which noise levels above $115 \mathrm{dBA}$ exceeded a 15 -minute interval. Therefore, there is no need for the drivers to be included in the HCP. Results for the Batch Plant drivers are shown in Table 2.

\section{Table 2: Batch Plant Dosimeter Results}

$\begin{array}{cccccc}\text { Worker } & \text { Job } & \text { Sample Duration } & & \\ 1 & \text { CDL Driver } & 9.9 & 82.7 & 44.9 & 84.2 \\ 2 & \text { CDL Driver } & 9.5 & 80.5 & 31.9 & 81.8\end{array}$

\subsection{Block Plant}

At the Block Plant, the noise levels exceeded both the action level and the PEL on both days. Refer to the TWA values in Table 3. Hence, the requirement for hearing protection.

\subsubsection{Adequacy of hearing protection}

The hearing protection currently used by Central has a rating of 33 . With this rating, an estimated exposure with was obtained using the following equation.

Estimated Exposure $(\mathrm{dBA})=\mathrm{TWA}(\mathrm{dBA})-[(\mathrm{NRR}-7) \times 50 \%]$ 
The estimated exposure using the NRR exceeded the action level of $85 \mathrm{dBA}$ for Worker 5 on both days. See Appendix E for calculations of overexposed workers. This is probably due to the close proximity of Worker 5 to the block press. See Figure 1. The estimated exposure did not exceed the PEL of $90 \mathrm{dBA}$ for any worker on either day at the Block Plant. There was no point at which noise levels above $115 \mathrm{dBA}$ exceeded a 15-minute interval. It was observed that two employees were not wearing hearing protection as required. Worker 3 was observed wearing hearing protection only some of the time and Worker 4 was observed wearing hearing protection most of the time.

According to employees, the workload during testing at the Block Plant was about half the typical values for both days due to problems with the block molds. The block press was down during repair of the block molds, which happened often during both days of testing. During full production, the block press would have been running more often and may have resulted in higher exposures. Therefore, employees at the Block Plant need to be included in the HCP and must be required to wear hearing protection during production.

In the summer months, the Block Plant is in peak production and employees work more than the typical 40 hours a week. Noise levels do not increase during peak production months, however, employees are exposed to these noise levels for a greater period of time, resulting in higher exposures.

The Block Plant has noise baffling quilts in the area surrounding the block press machinery. See Figure 1. Spot reading were taken on both sides of the noise baffling quilts. On the side nearest the block press, a reading of 95.9 was recorded and a reading of 89.8 was recorded on the opposite side. Readings were taken one inch away from the quilts. This $6.1 \mathrm{dBA}$ 
difference shows the effectiveness of the noise baffling quilts. The work station of Worker 5, however, is located between the block press machinery and the noise baffling quilt, making the quilts ineffective.

Results for the three Block Plant employees are shown in Table 3.

\section{Table 3: Block Plant Dosimeter Results}

\section{Day 1}

\begin{tabular}{|c|c|c|c|c|c|c|}
\hline Worker & Job Location & $\begin{array}{c}\text { Sample } \\
\text { Duration } \\
(\mathrm{hrs})\end{array}$ & Leq & $\begin{array}{c}\text { Dose } \% \\
(10-h r)\end{array}$ & $\begin{array}{l}\text { TWA } \\
(\mathrm{dBA})\end{array}$ & $\begin{array}{l}\text { Estimated } \\
\text { Exposure } \\
\text { with } \\
\text { protection }\end{array}$ \\
\hline 3 & Block Plant (General) & 10.3 & 94.8 & 249.7 & 96.6 & 83.6 \\
\hline 4 & $\begin{array}{c}\text { Belt Line/Cuber } \\
\text { Block Mold/Inside }\end{array}$ & 10.0 & 90.9 & 140.7 & 92.5 & 79.5 \\
\hline 5 & Mixer & 9.7 & 97.0 & 319.6 & 98.4 & 85.4 \\
\hline \multicolumn{7}{|c|}{ Day 2} \\
\hline 3 & Block Plant (General) & 10.2 & 92.2 & 173.3 & 94.0 & 81.0 \\
\hline 4 & $\begin{array}{c}\text { Belt Line/Cuber } \\
\text { Block Mold/Inside }\end{array}$ & 10.2 & 93.7 & 212.7 & 95.4 & 82.4 \\
\hline 5 & Mixer & 9.8 & 98.7 & 406.6 & 100.1 & 87.1 \\
\hline
\end{tabular}

\section{Conclusion}

On October 24, 2016 and on November 16, 2016, three of five sampled workers were exposed to greater than $85 \mathrm{dBA}$. None of the two workers in the Batch Plant were overexposed and three of the three workers in the Block Plant were overexposed.

Three of five sampled workers were exposed to greater than 90 dBA and OSHA would require that their exposures be reduced to less than $90 \mathrm{dBA}$. 
Hearing protectors supplied to overexposed workers should provide adequate protection if fitted and worn properly. Only one of the overexposed workers wore hearing protection during the entire shift, which was Worker 5 in the Block Plant. Worker 3 and 4 were occasionally observed not wearing hearing protection.

The company hearing conservation program had the following deficiencies: compliance and storage of the muffs.

OSHA requires that Central Supply institute an effective hearing conservation program for employees who are exposed to noise levels above the OSHA action level of $85 \mathrm{dBA}$ (see Table 3).

All over-exposed employees are currently required to wear hearing protection. However, compliance was poor. The current hearing protection of $33 \mathrm{NRR}$ is adequate for reducing levels below the PEL if the ear plugs are worn properly.

\section{Recommendations}

There are three control methods for mitigating noise: engineering controls, administrative controls, and personal protective equipment. Much industrial noise can be controlled using one or any combination of these methods. The best long-term solution to control noise hazards is engineering controls. These controls aim to treat the noise at the source. When engineering controls are not feasible, administrative controls should be considered next. Administrative controls are methods to relocate the worker to a safe area. When engineering and administrative controls are not possible, the worker must be protected with personal protective equipment.

\subsection{Administrative}

Administrative controls are measures taken to reduce duration of high noise exposure levels, such as changes in work schedules or worker operations. If employees at the Block Plant 
worked an 8-hour shift instead of a 10-hour shift, exposures would be below the 90 dBA PEL with hearing protection. Exposures would also be below the $85 \mathrm{dBA}$ action level for all employees, except for Worker 5 on Day 2. See Appendix F. If the duration was reduced to 4 hours, the exposures while wearing correct hearing protection would be below both the action level and PEL.

Currently, the duty of cleaning inside the cement mixer is rotated amongst the Block Plant employees. However, it is also recommended that workers rotate positions in order to distribute the amount of time each employee spends in close proximity to the block press. Worker 5, who spent the majority of the shift in close proximity to the block press, returned the highest TWA on both days. These levels exceeded the action level and approached the PEL with the use of proper hearing protection. See Table 3.

\subsection{Engineering Controls}

Engineering controls are measures taken to remove the hazard from the workplace, such as modifications or replacements at the noise source or interrupting the noise path. The Block Plant currently has noise baffling quilts hanging on the surrounding walls in the location of the block press. These quilts reduced the sound level by $6.1 \mathrm{dBA}$. If Worker 5 was behind the noise baffling quilts, the exposure while wearing hearing protection would be below both the action level and PEL. It is recommended to move the work station of Worker 5 to an area behind the noise baffling quilts.

No additional engineering controls are recommended.

\subsection{Personal Protective Equipment}

Personal Protective Equipment is a protective barrier of clothing or equipment designed to protect the body from exposure to hazards. Central currently provides hearing protection with 
a NRR of 33. This is sufficient in reducing noise levels below the OSHA PEL. Central requires hearing protection to be worn at the Block Plant. However, two employees were observed not to comply with this requirement. Therefore, there is a need for an enforcement plan.

No additional PPE is recommended.

\subsection{Additional Recommendations}

In addition to the potential noise hazard, it was observed that the amount of dust produced in the Block Plant may be a potential problem. There are areas that have accumulated large amounts of cement dust. Exposure to cement dust can irritate the skin, eyes, nose, throat, and respiratory system. Moreover, there may be a exposure to silica, which can lead to silicosis and lung cancer. If sampling shows high exposures, the Company should strongly consider improved ventilation. Also, cement dust can damage equipment. It is recommended to practice and enforce good housekeeping.

It was also observed that employees have food out in the Block Plant next to their work stations. There is a break room located inside the building surrounded with sound proofing blocks. However, employees do not use the break room to eat. This is probably to keep up with production. The Block Plant shuts down during maintenance and at the end of the day only. By not utilizing the break room for eating, employees pose the potential problem of ingesting cement dust. It is recommended to prohibit food outside of the break room. There is also a concern with the amount of dust produced during the cleaning process of the mixer. While inside the mixer, which would be considered a confined space, the worker uses an air chisel to remove the excess buildup of cement. Employees are not required to wear any type of respirator during this process. Sampling is recommended to determine if dust levels exceed OSHA standards. 
Noise levels were sampled inside the mixer during the cleaning process. The highest recorded Lmax during this time was $103.2 \mathrm{dBA}$. 
9. Works Cited

Ali, Ahmad. "Noise-Induced Hearing Loss at Cement Company, Nigeria." Online Journal of Medicine and Medical Science Research. 1.3 (2012): 49-54. Web. July 2016.

Martínez, Luis F. "Can You Hear Me Now? Occupational Hearing Loss, 2004-2010." Monthly Labor Review. 135.7 (2012): 48-55. Print.

"United States Department of Labor." Occupational Safety and Health Administration. N.p.,n.p. Web. 20 Mar. 2017.

Hearing Conservation. Washington, D.C: Occupational Safety and Health Administration, United States Dept. of Labor, 1995. Internet resource. 
10. Appendix A: SLM Results at Batch Plant

Table 4: SLM

Readings Operator

Distance from Trucks

$\begin{array}{cll}\text { Truck } & & \text { Leq } \\ 1 & & 93.4 \\ 2 & 95.3 \\ 3 & 95.8 \\ 4 & 97.8\end{array}$




\section{Appendix B: Adjustments for shifts $>8$ hours}

The action level can be adjusted using the following equation:

[I reformatted this appendix for you on the last review I sent you

$$
\mathrm{AL}=\left[\begin{array}{l}
\log _{10}(8 / \mathrm{t}) \\
-\log _{10}(2)
\end{array}\right]+85
$$

where, $\mathrm{t}=$ work shift in hours

The permissible exposure limit can be adjusted using the following equation:

$\mathrm{PEL}=\left[\begin{array}{l}\log _{10}(8 / \mathrm{t}) \\ \hdashline \log _{10}(2)\end{array}\right]+90$

where, $\mathrm{t}=$ work shift in hours

The noise dose (D) and time-weighted average can be adjusted using the following equations:

$\mathrm{D}=100(\mathrm{C} / \mathrm{T})$

where, $\mathrm{C}$ is the total length of the workday, and

where, $\mathrm{T}$ is the reference duration calculated using:

$$
\mathrm{T}=\frac{10}{2^{(\operatorname{Lavg}-88.4) / 5}}
$$

And,

$\mathrm{TWA}=16.61 \log _{10}(\mathrm{D} / 100)+90$ 


\section{Appendix C: Dosimetry Results}

Batch Plant :
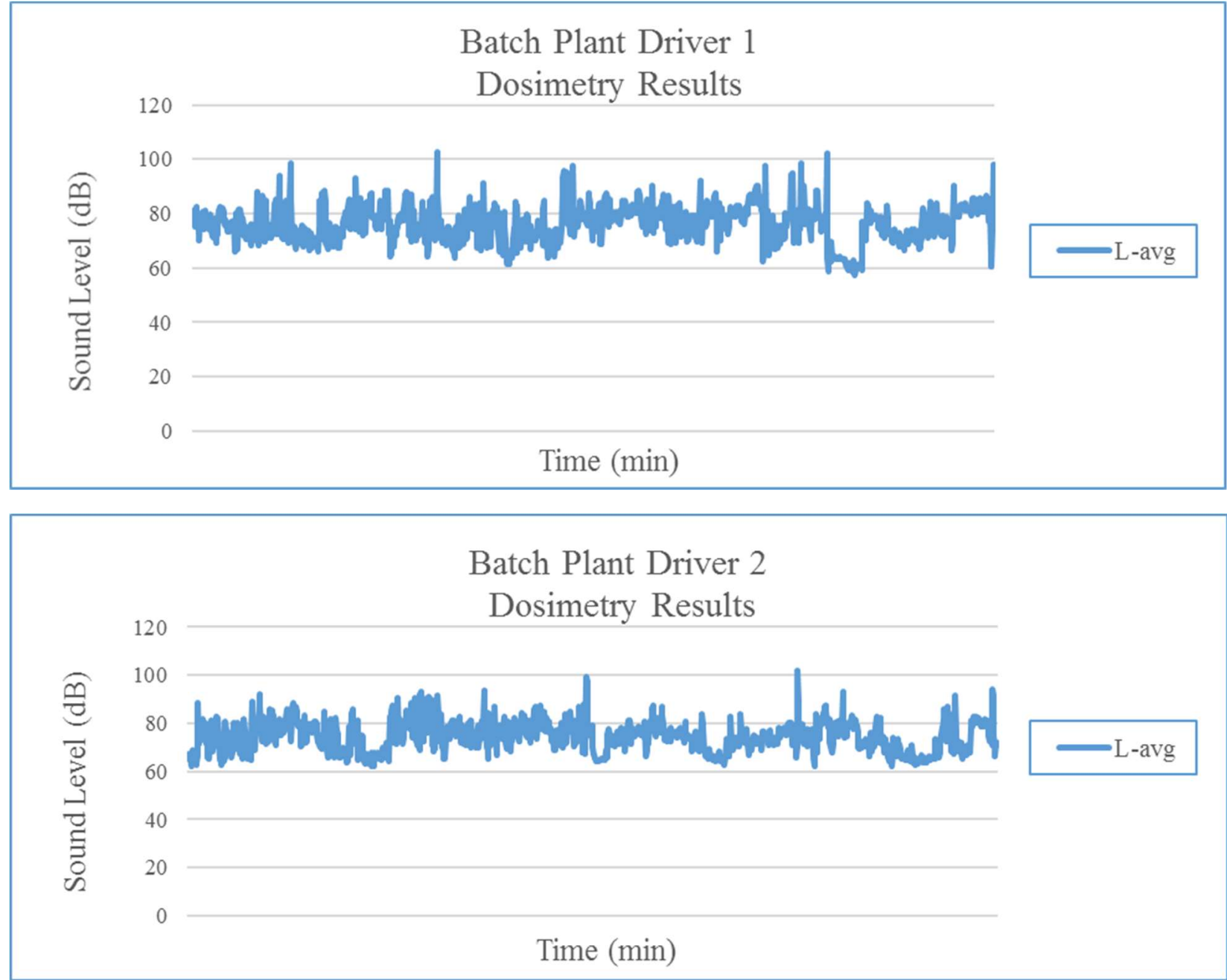

Block Plant Day 1 :

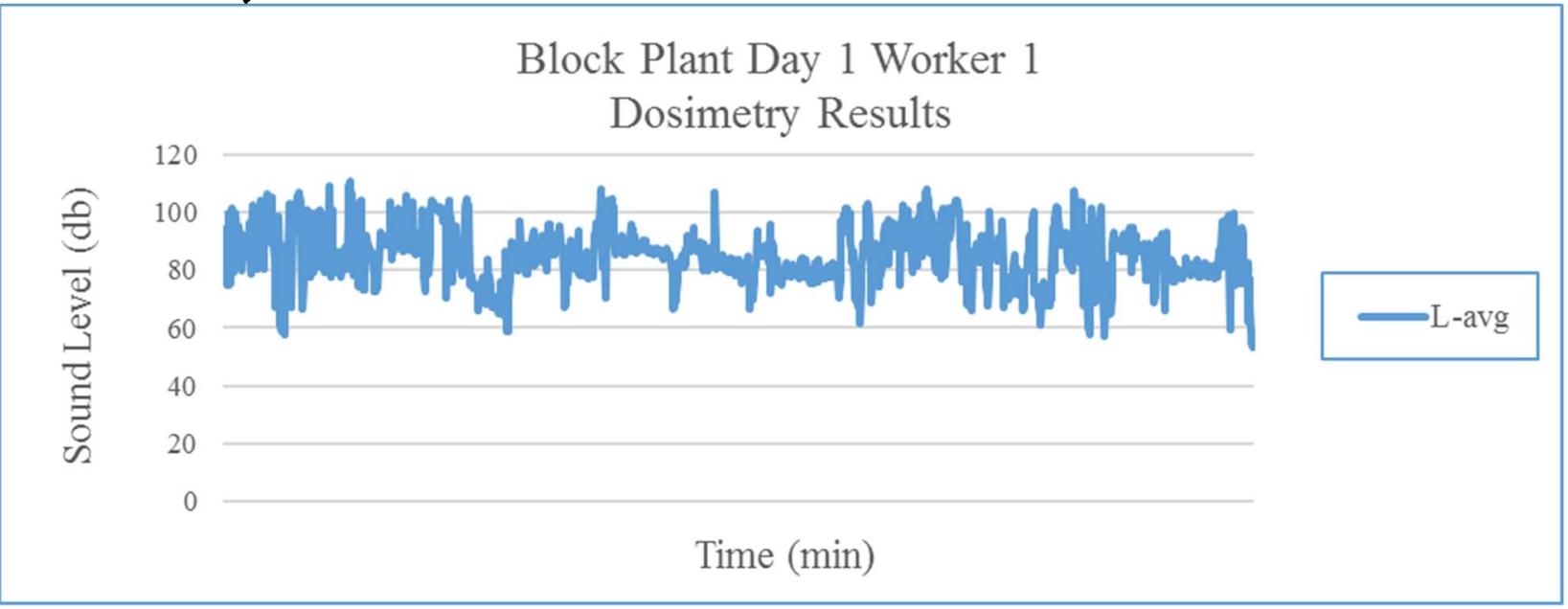



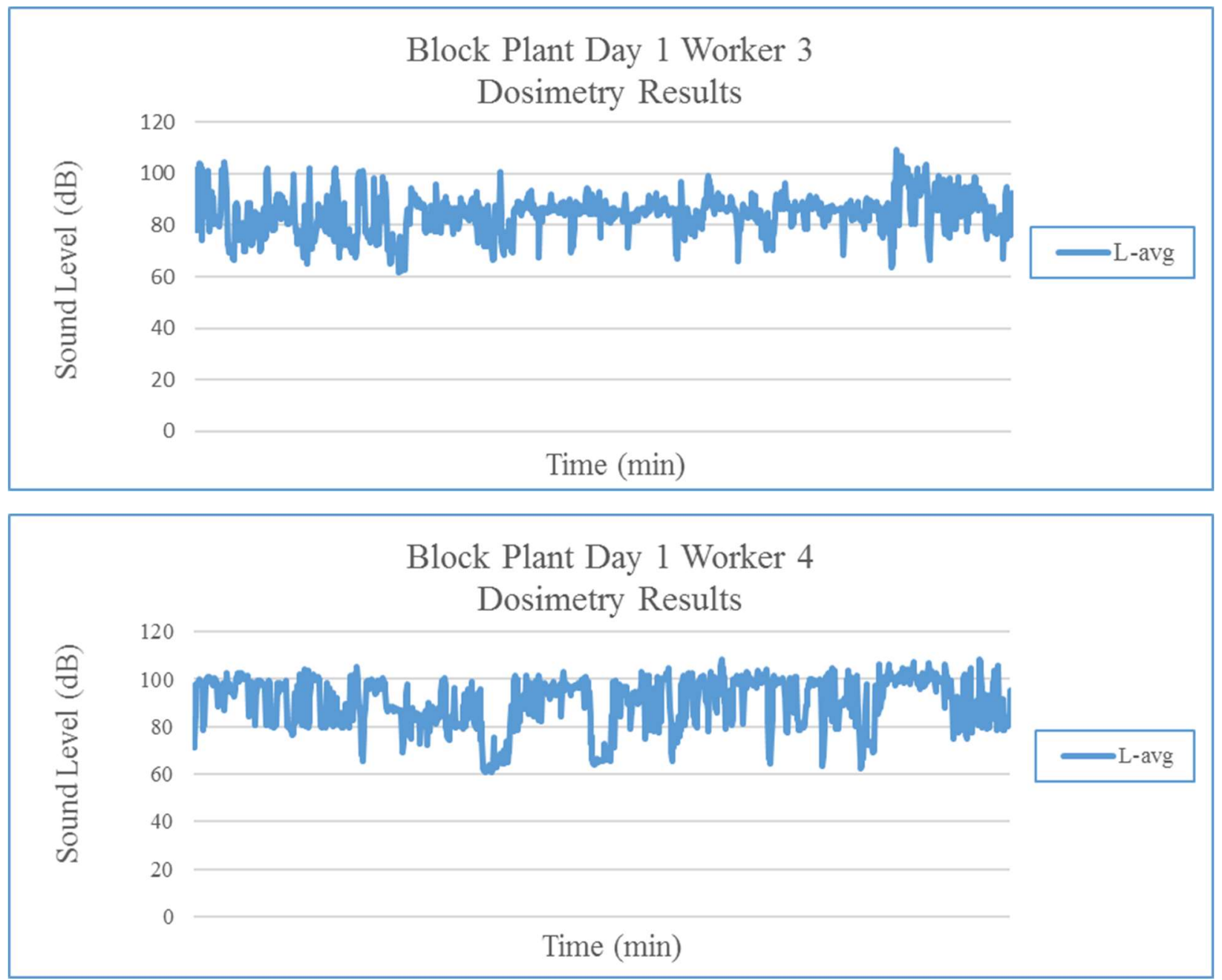

Block Plant Day 2:

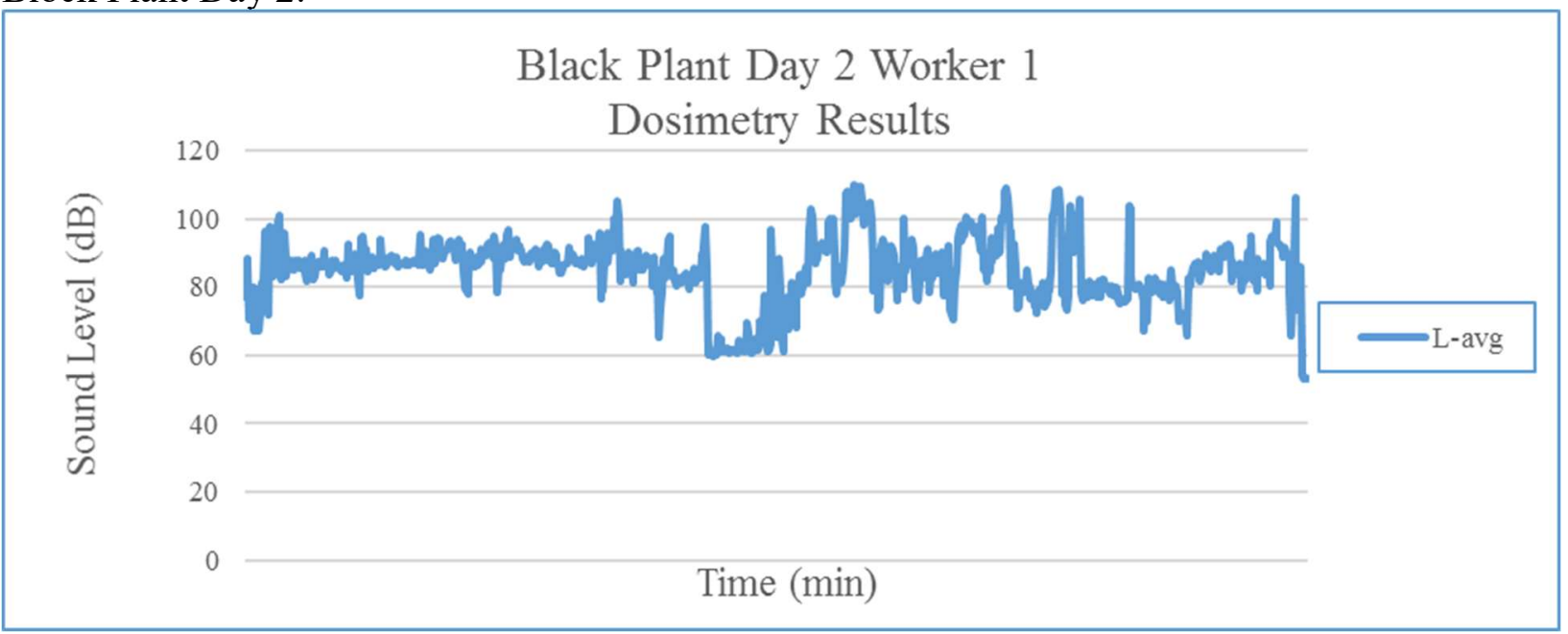



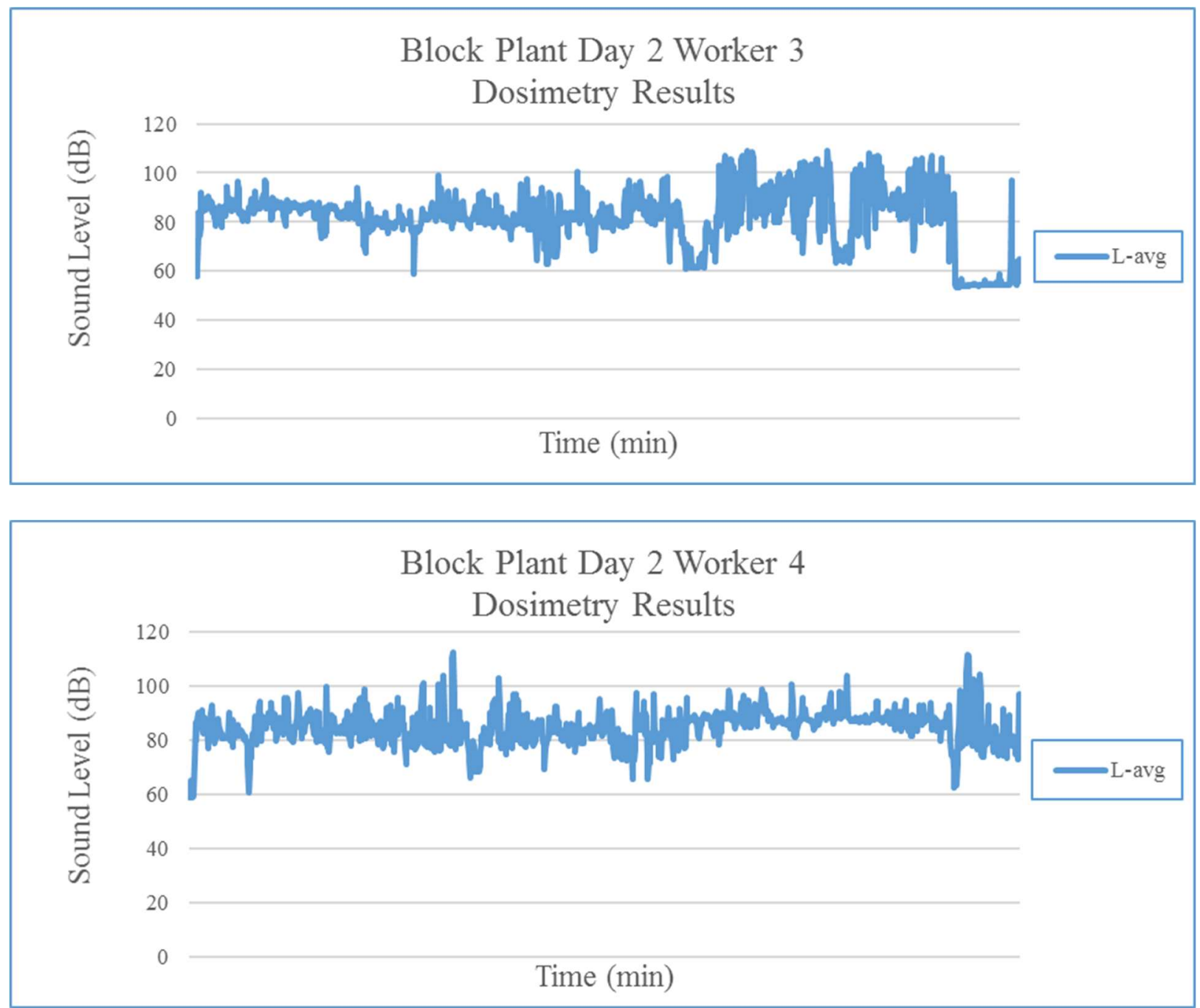
13. Appendix D: Calibration Results

All pre- and post-calibrations were taken with the Cal200 calibrator at a level of $114 \mathrm{dBA}$ and a frequency of $1000 \mathrm{~Hz}$. Results are shown in Tables 5 and 6.

Table 5: Batch Plant

Calibration Results

$\begin{array}{ccc}\text { Worker } & \text { Pre } & \text { Post } \\ 1 & 0 & 0.1 \\ 2 & -0.1 & -0.1\end{array}$

\section{Table 6: Block Plant Calibration Results}

\begin{tabular}{ccccc} 
& \multicolumn{2}{c}{ Day 1 } & \multicolumn{2}{c}{ Day 2 } \\
Worker & Pre & Post & Pre & Post \\
1 & -0.1 & 0 & 0 & -0.2 \\
2 & 0 & -0.3 & 0.2 & 0 \\
3 & -0.2 & 0.1 & -0.1 & 0
\end{tabular}


14. Appendix E: Calculations of Overexposed Workers

\section{Calculations of Estimated Exposure with Hearing Protection for Worker 5}

Day 1 Estimated Exposure with protection $=$ TWA $-\left[\begin{array}{lllll}(\mathrm{NRR} & -7 & \mathrm{~N}^{2} & / & 2\end{array}\right]$

$\left.=98.6-\left[\begin{array}{lllll}33 & -7\end{array}\right) / 2\right]$

$=98.6-13$

$=85.6$

Day 2 Estimated Exposure with protection $=$ TWA $-\left[\begin{array}{lllll}(\mathrm{NRR} & -7 & \mathrm{~N}^{2} & / & 2\end{array}\right]$

$=100.3-\left[\begin{array}{lllll}(33 & -7 & ) & / & 2\end{array}\right]$

$=100.3-13$

$=87.3$ 
15. Appendix F: Dosimetry Results for an 8-Hour Shift

Table 7: Day 1 Block Plant Dosimeter Results for an 8-Hour Shift

\begin{tabular}{|c|c|c|c|c|c|c|}
\hline Worker & Job Location & $\begin{array}{c}\text { Sample } \\
\text { Duration } \\
\text { (hrs) }\end{array}$ & Leq & $\begin{array}{l}\text { Dose } \\
(8-h r)\end{array}$ & $\begin{array}{l}\text { TWA } \\
\text { (dBA) }\end{array}$ & $\begin{array}{l}\text { Estimated } \\
\text { Exposure } \\
\text { with } \\
\text { protection }\end{array}$ \\
\hline 1 & Block Plant (General) & 8.0 & 94.8 & 194.5 & 94.8 & 81.8 \\
\hline 2 & Belt Line/Cuber & 8.0 & 90.9 & 113.3 & 90.9 & 77.9 \\
\hline 3 & Block Mold/Inside Mixer & 8.0 & 97.0 & 263.9 & 97.0 & 84.0 \\
\hline
\end{tabular}

Table 8: Day 2 Block Plant Dosimeter Results for an 8-Hour Shift

\begin{tabular}{|c|c|c|c|c|c|c|}
\hline Worker & Job Location & $\begin{array}{c}\text { Sample } \\
\text { Duration } \\
(\mathrm{hrs})\end{array}$ & Leq & $\begin{array}{l}\text { Dose } \\
(8-h r)\end{array}$ & $\begin{array}{c}\text { TWA } \\
(\mathrm{dBA})\end{array}$ & $\begin{array}{l}\text { Estimated } \\
\text { Exposure } \\
\text { with } \\
\text { protection }\end{array}$ \\
\hline 1 & Block Plant (General) & 8.0 & 92.2 & 135.7 & 92.2 & 79.2 \\
\hline 2 & Belt Line/Cuber & 8.0 & 93.7 & 167.0 & 93.7 & 80.7 \\
\hline 3 & Block Mold/Inside Mixer & 8.0 & 98.7 & 334.0 & 98.7 & 85.7 \\
\hline
\end{tabular}

